\title{
Rescaling the energy label for washing machines: an opportunity to bring technology development and consumer behaviour closer together
}

\author{
Alicia Boyano • Nieves Espinosa • \\ Alejandro Villanueva
}

Received: 6 March 2019 / Accepted: 13 September 2019/Published online: 24 October 2019

(C) The Author(s) 2019

\begin{abstract}
Washing machines have in recent years incorporated programmes that are very energy- and waterefficient, but this entails a long programme duration, often beyond $4 \mathrm{~h}$. These are also the programmes that the manufactures use to define, test and declare the overall water and energy efficiency of the machines. In response to these developments, there is evidence that consumers are reluctant to use excessively lengthy programmes, even if they are aware that the programmes are more energy-efficient.

This paper analyses this divergence of programme offer and programme use, which jeopardises the energy efficiency policy objectives for these appliances in the European Union (EU). The paper explores several policy measures to address this divergence, discussed in the context of the revision of the Ecodesign and Energy Labelling regulations that apply to washing machines in the EU.

Three different measures are studied: the provision of information about the programme duration on the energy label, the inclusion of time as an intrinsic parameter of the energy efficiency index calculations and the setting of a programme duration cap.

The paper concludes that introducing programme duration as an additional parameter of the energy efficiency index would result in the highest energy savings. However, this scenario is associated with significant
\end{abstract}

A. Boyano $(\bowtie) \cdot$ N. Espinosa $\cdot$ A. Villanueva European Commission, Joint Research Center (JRC), Ed. EXPO, Inca Garcilaso 3, 41092 Seville, Spain uncertainties since competition among the manufacturers for a better energy label classification will not solely focus on energy efficiency aspects, and the outcome of such competition is unclear. The other two measures investigated are less effective but would also deliver savings. A programme duration cap would bring energy savings if consumers are aware of their existence and select the now shorter yet energy-efficient programmes more often. The provision of programme duration information on the energy label would also be effective but requires that consumers are able to correctly understand it.

Keywords Washing machines $\cdot$ Ecodesign $\cdot$ Energy Labelling

\section{Introduction and context}

Energy efficiency first is a central principle of the Energy Union strategy (EU Parliament 2015). The Energy Labelling regulation, in synergy with mandatory minimum efficiency requirements of Ecodesign, is a policy tool that aims at increasing the energy efficiency of energy-related products and is an effective way to cut emissions, bring savings to consumers and reduce the EU's fossil fuel import dependency. Since their introduction, the success

e-mail: alicia.boyano-larriba@ec.europa.eu 
of Energy Labelling and Ecodesign have encouraged the development of ever more energy-efficient products, describing product performance to allow consumers to make informed purchase decisions and driving competition and innovation towards better-performing products. Recent consumer surveys (Alborzi et al. 2017a; Schmitz et al. 2016; Pakula and Stamminger 2015; Kruschwitz et al. 2014) show that about $85 \%$ of European citizens look at energy efficiency labels when they purchase products (Europa press 2017).

The introduction of the label has not taken place without challenges: in the EU, the technology development triggered by the Ecodesign and Energy Labelling regulations has in some cases outpaced the speed of the update of regulatory development, forcing an extension of the top label classes beyond $A$ to $G$ and introducing A+, A++ and A+++. Some studies (Ecofys 2013; Russo et al. 2018; Europa press 2017) suggest that having the best-performing appliances in the top $\mathrm{A}+, \mathrm{A}++$ and $\mathrm{A}+++$ categories can be misleading to consumers when looking across products that remain in the A to $\mathrm{G}$ range. To address these differences, the revised Energy Label "Framework" Regulation (1369/2017) (Regulation (EU), 2017) mandates a rescaling of energy classes from A to $\mathrm{G}$ in future Energy Labelling revisions. This affects the revision of regulations (EU) No 1015/2010 (Ecodesign) (EU 2010a) and regulation (EU) No. 1061/2010 (Energy Labelling) (EU 2010b) of household washing machines, which has taken place between 2014 and 2019. The revision has been an opportunity to revisit other Ecodesign or Energy Labelling requirements such as programme duration, which interfere with the goal of achieving energy savings.

This paper focuses specifically on the relationship between the use of resources (energy, water) and the duration of the programmes in washing machines. In the Ecodesign and Energy Labelling regulations that have been in force since 2011, the programme duration has not been part of any requirement or specified on the label. However, evidence suggests that it has the potential to change the purchase decisions of consumers, it is crucial to the selection of programmes and it overall plays a major role in achieving real energy savings.

This work investigates specifically the role of programme duration in energy saving and assesses the environmental and economic impacts of three potential options to include this information in the policy, including modification of the energy efficiency index to include programme duration as an additional parameter, provision of programme duration information on the energy label and determination of a programme duration cap by means of Ecodesign. The main sources of data presented in this article are two detailed technical reports from the Joint Research Centre (JRC 2017a, b). The reports have underpinned the discussions held by stakeholders in the context of the revision of regulations EU/ 1015/2010 (Ecodesign) and EU/1061/2010 (Energy Labelling) of household washing machines, led by the European Commission between 2014 and 2019.

\section{Literature review}

A number of consumer magazines in European countries such as UK's Which?, Germany's Stiftung Warentest, France's Que choisir, Danish Taenk! or Spanish Compra maestra have recently discussed and made consumers aware of the relation between the programme duration and energy consumption. They highlight that, in reality, in recent years, consumers have not been using the most energy-efficient washing programmes because they last too long.

Figure 1 shows the specific energy consumption of the most efficient programmes of average washing machines in the EU. Consumption has been halved from $0.245 \mathrm{kWh} / \mathrm{kg}$ in 1997 to $0.120 \mathrm{kWh} / \mathrm{kg}$ in 2013 . It should be noted that the reference for the declaration of the energy consumption changed in 2011. From 2011 onwards, energy consumption has been measured in a combination of standard cotton programmes at $40{ }^{\circ} \mathrm{C}$ and $60{ }^{\circ} \mathrm{C}$ with half and full loads whereas previously, it was measured only at $60^{\circ} \mathrm{C}$ full load. When comparing the distribution of the average specific energy consumption per cycle in 1997 with that of 2013, it is evident that the industry has optimised washing machine models to comply with the energy consumption requirements of the most challenging energy efficiency classes.

However, Fig. 1 shows that the energy consumption per cycle has not experienced such strong decrease and instead has very moderately decreased over recent years. This is due to the observed increase in the rated capacity in the same reference years from 1997 to 2013. Two main developments explain this divergence: firstly, an extension of the programme duration, and secondly, an increase of the washing capacity. These variables are also related to each other.

In a decade, the programme duration in small-rated capacity washing machines has doubled, and it has 
Fig. 1 Trends of the specific energy consumption per kilogramme of rated capacity and energy consumption per cycle of European washing machines

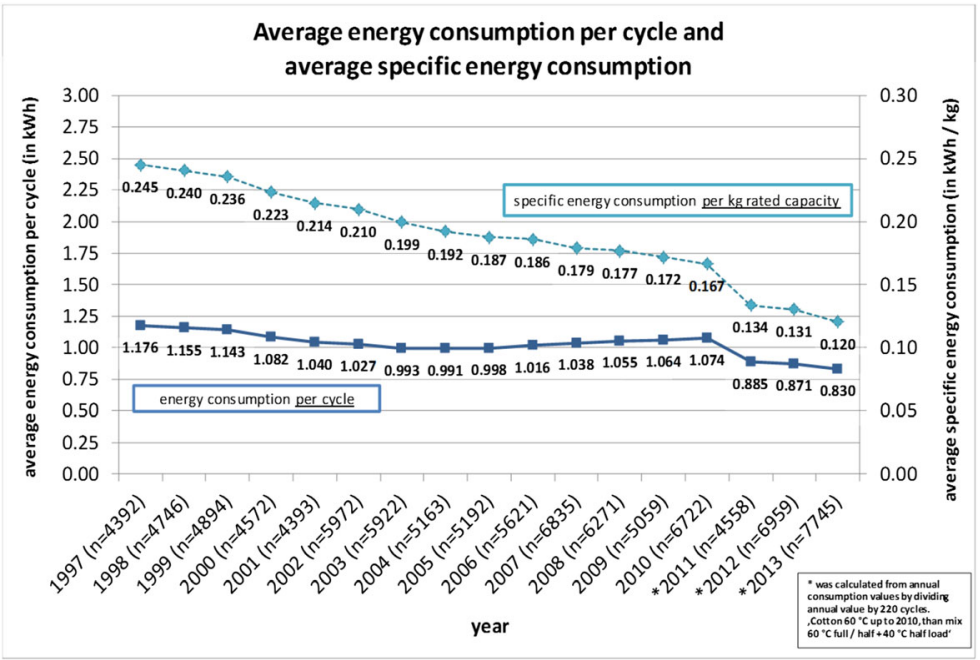

doubled and even tripled for the larger washing machines (taking up to $6 \mathrm{~h}$ for a full load). Manufacturers have discovered that increasing the programme length is a more energy-efficient way to achieve washing performance than increasing the temperature. This way, machines obtain a better energy efficiency class. Machines continue to offer short washing programmes, but they normally require higher temperatures, use more energy and in some cases are not recommended for full loads.

The programme duration also depends on the rated capacity of the washing machines. The rated capacity, as declared by the manufacturer, is defined as the maximum mass in kilogrammes of dry textiles (at $0.5 \mathrm{~kg}$ intervals) which can be treated in one washing cycle of a household washing machine (JRC 2017a). Washing machines with larger capacity need longer programme durations, but their specific energy consumption is lower, getting better EEI and energy label classifications.

Figure 2 shows the development of washing machine capacities on the European market. The average capacity of the machines (in kilogrammes of cotton) has increased from about $4.8 \mathrm{~kg}$ in 1997 to $7.04 \mathrm{~kg}$ in 2013. This trend seems to have started in 2002 and continues until today. The reason for this trend is not clear considering that European household size is decreasing. Therefore, it is assumed that there must be other reasons that incentivise the market to develop increasingly large washing machines. In more detail, the distribution of the average rated capacity of 7745 washing machines in the year 2013 shows that around $31 \%$ of washing machine models have a capacity of $6.5-7 \mathrm{~kg}$, followed by $24 \%$ with a capacity of $7.5-$
$8 \mathrm{~kg}$ and $23 \%$ at $5.5-6 \mathrm{~kg}$. In 2013 , the $5-\mathrm{kg}$ models only constitute a share of around $8 \%$. Meanwhile, there were already some models with $9 \mathrm{~kg}, 10 \mathrm{~kg}$ and $11 \mathrm{~kg}$ capacity on the market.

Moreover, it is important to note that consumer behaviour has not changed during these years. A literature review undertaken in the context of the regulation's revision revealed that the average loading of European consumers has remained roughly constant (approximately $3.4 \mathrm{~kg}$ per cycle) for a decade despite the increasing rated capacity of the appliances (JRC 2017a).

Examining these values, and considering that an average consumer does not fully load the washing machine, it seems that the real specific energy consumption (kilowatt hour per kilogramme of laundry) of an average cycle is indeed higher than the declared specific energy consumption (value displayed in the product information sheet and documentation accompanying the washing machines at the point of sale).

Addressing the problems caused by long programme durations can indirectly tackle the mismatch between the capacity of the washing machines offered by the manufacturers and the capacity demanded by the consumers. Some possible ways to do so are examined in this paper. For example, information about the programme duration is not currently shown on the energy label. This could be preventing consumers who want to prioritise this aspect of the washing cycle from making an informed purchase decision. Another example would be a programme duration cap. Larger washing machines will need to increase the washing temperature to wash with programme durations shorter than the programme 
Fig. 2 Trend of the average rated capacity of the washing machines, in kilogrammes of cotton textiles

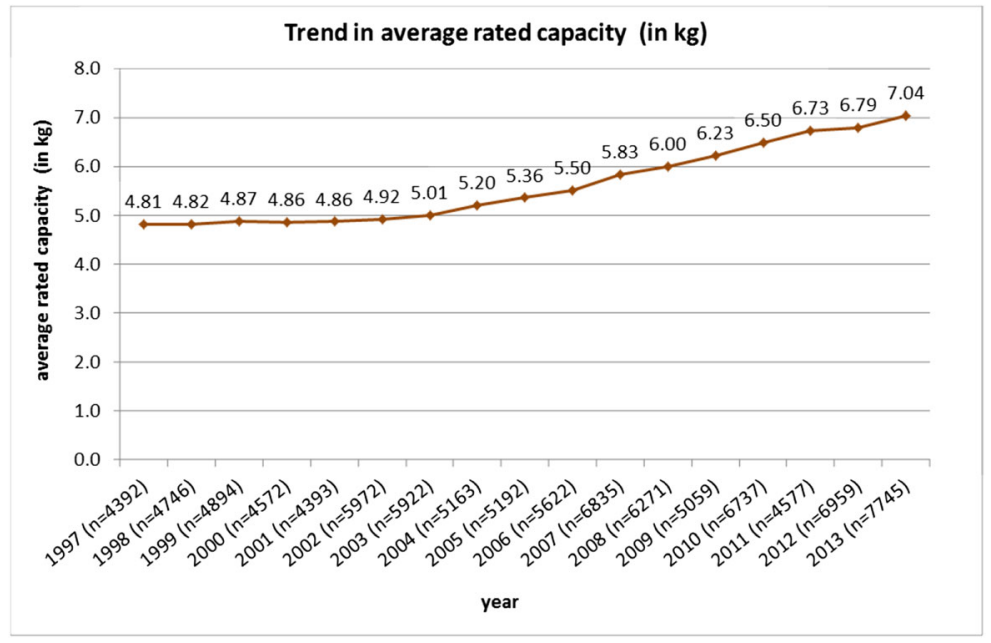

duration cap, getting a worse energy label classification. This fact can affect the sales and the number of larger washing machines put on the market.

User behaviour

A better insight into how consumers interpret the energy label information, both before and after purchase, is crucial to estimate the potential energy savings of Ecodesign and Energy Labelling policy more realistically.

According to one of the latest user surveys on the use of washing machines (JRC 2017a), this observed trend for longer cycles is in general not welcomed by consumers.

The standard $40{ }^{\circ} \mathrm{C} / 60{ }^{\circ} \mathrm{C}$ cotton programmes are the ones tested for the purpose of declaration of energy efficiency, as prescribed in the current regulations. These programmes are designed to maximise energy efficiency. This is essentially done by reducing the washing temperature to $30-35^{\circ} \mathrm{C}$, loading to the maximum and increasing the mechanical action by prolonging the programme duration. However, all washing machine manufacturers offer also similar programmes (normal $40{ }^{\circ} \mathrm{C} / 60{ }^{\circ} \mathrm{C}$ cotton programmes) that wash at higher temperatures $\left(>40{ }^{\circ} \mathrm{C}\right)$ and are shorter (for instance, $2 \mathrm{~h}$ instead of $4 \mathrm{~h}$ ).

Consumers are reluctant to use programmes that last longer than $3 \mathrm{~h}$, which is reflected by the lower use of the current standard cotton programmes in comparison to the normal cotton programmes.

According to Waechter et al. (2015), the energy label draws attention towards energy information in general, but its effect on the consumer's actual product choice seems to be low. Some explanations may be that the label provides energy efficiency information under the best possible conditions but fails to describe actual energy consumption under the conditions that are customary to the user's needs. For instance, a user looking for a smaller capacity machine for a single-person household may find that smaller machines $(5-7 \mathrm{~kg})$ present worse labels (e.g. A, A+) than large machines (A+++ for 10-13 kg). The findings suggest that if the information related to the actual energy consumption is not conveyed on the label, the final energy consumption by users may not decrease, because excellent ratings on energy efficiency (e.g. A+++) do not automatically imply less consumption in real life.

Several studies demonstrate that consumers do not make much use of the energy-saving programmes (Alborzi et al. 2017b; Scheid et al. 2017; Conrady et al. 2014). Such programmes are the only ones reported on the energy label. This, however, is not fully known to users who assume that the information provided on the label is representative of all the programmes of the machine. Consumers are essentially not aware of the relationship between longer times and lower energy consumption.

Given this evidence, if the primary overall goal of using the label is to save energy, one may suggest that the label should ideally convey to the user not only information about the consumption of appliances under optimal conditions, but also under conditions as close as possible to real life. This way, the technical development and optimisation of machines in real-life conditions would also save energy in reality. 


\section{Methodology}

This section presents the methodological aspects of the estimation of environmental and economic impacts of the three policy scenarios that have been devised to introduce the factor 'programme duration' as a parameter in the Ecodesign and Energy Labelling requirements.

Firstly, the energy efficiency index (EEI) currently used to define and benchmark washing machine's efficiency is explained. Secondly, a description of the policy measures proposed to tackle the problem of lasting programme durations is presented, followed by the description of the model. Finally, the estimated market evolution for each of the scenarios is presented.
Energy efficiency index

The current energy efficiency index (EEI) allows washing machines to be classified according to their energy performance in one of the three currently available energy efficiency classes (A+, $\mathrm{A}++$ or $\mathrm{A}+++)$. This parameter is based on a combination of cycles which clean normally soiled cotton laundry. These programmes are the standard $40{ }^{\circ} \mathrm{C}$ cotton programme and the standard $60{ }^{\circ} \mathrm{C}$ cotton programme at full and half loads and the energy consumption of the low power modes.

The following formula to calculate the EEI is established in IEC/EN 60456:2011:

$\mathrm{AE}_{C}=E_{t} \times 220+\frac{\left\{P_{l} \times T_{l} \times 220+P_{o} \times\left[525600-\left(T_{t} \times 220\right)-\left(T_{l} \times 220\right)\right]\right\}}{60 \times 1000}$

where $\mathrm{AE}_{C}=$ weighted annual energy consumption of the household washing machine; $E_{t}=$ weighted energy consumption for the standard cycles (standard cotton $40{ }^{\circ} \mathrm{C}$ and standard cotton $60{ }^{\circ} \mathrm{C}$ ), in kilowatt hour, and rounded to three decimal places; $P_{l}=$ weighted power in 'left-on mode' for the standard washing cycles, in $W$, and rounded to two decimal places; $P_{o}=$ weighted power in 'off mode' for the standard washing cycles, in $W$, and rounded to two decimal places ('weighted' makes here the reference to the process carried out when applying the standards; each programme is run several times and then their energy consumptions weighted); $T_{t}$ $=$ programme time for the standard cleaning cycle, in minutes, and rounded to the nearest minute; $T_{l}=$ measured time in 'left-on mode' for the standard cleaning cycle, in minutes, and rounded to the nearest minute; and $220=$ total number of washing cycles per year.

The index is obtained by dividing this annual energy consumption by the standard annual energy consumption which depends on the rated capacity of the machines. The formula reads as follows:

$\mathrm{EEI}=\frac{\mathrm{AE}_{C}}{\mathrm{SAE}_{C}} \times 100$

where $\mathrm{SAE}_{C}=$ standard annual energy consumption of the household washing machine being given by the following formula

$\mathrm{SAE}_{C}=47.0 \mathrm{c}+51.7$ where $c=$ rated capacity in kilogrammes cotton at standard cotton $40{ }^{\circ} \mathrm{C}$ or standard cotton $60{ }^{\circ} \mathrm{C}$ programme.

As observed, the EEI of a washing machine increases when the energy consumption of the cycle and the energy consumption of the associated low power modes increase and decreases when the rated capacity of the machines increases.

\section{Description of the policy measures}

As explained in the previous sections, consumers are reluctant to select energy-saving programmes if they consider their duration is excessive. In the context of revision of the EU Ecodesign and Energy Labelling regulations, several measures have been proposed to avoid or even reverse this behaviour.

Washing machines currently offer a wide range of washing programmes, intended for different purposes and with different washing performances. The latest consumer behaviour survey available (Alborzi et al. 2017b) indicates that cotton programmes are by far the most used programmes in the EU, but also among the programmes with the highest average energy consumption. For this reason, declarations of energy use in the EU regulations have used cotton programmes as the reference, including the 2014-2019 revision. The option of widening the scope of the regulations to include the performance of all washing programmes offered by 
machines would result in a very large, long and costly testing process and difficulties to standardise washing programmes that are brand- or machine-specific, or rarely offered.

The policy measures selected in this paper are the outcome of a thorough analysis of a large number of possible measures, as detailed in JRC (2017a), involving a wide range of stakeholders across the European Union. The options with the highest potential for delivering energy savings, while remaining feasible to implement as part of the Energy Label regulation, are presented in this section.

The possible policy measures may be divided into three groups:

(a) Informative measures that aim at providing a more transparent indication of the programme duration to the consumers (e.g. information about the duration of the energy-saving programmes on the energy label and in the instruction booklet). This measure will be modelled below under the 'information on the label' scenario.

This measure has limitations due to the relatively inflexible layout of the energy label. The main information related to the energy consumption and energy efficiency classification is communicated in the upper part of the label and the duration would be included in the bottom half, along with other performance characteristics, or in the product information sheet that can be obtained through the QR code. According to Brazil and Caulfield (2017), only the information displayed in the upper part of the energy label can be easily remembered by most consumers.

(b) A modification of the EEI calculation to include an additional parameter related to programme duration. This measure will be modelled below under the ' $\mathrm{EEI}_{\mathrm{E} \& \mathrm{t}}$ ' scenario.

The current EEI is a measure of the energy efficiency of the machine to reach a certain washing performance. According to the so-called Sinner's Circle (Textile testing institute 2019), the washing performance depends essentially on four factors: temperature, chemistry, time and mechanics. The same level of washing performance can be achieved with different contributions of each of the four factors. When a washing machine is tested, the chemistry factor (related to the composition of the detergent) is fixed. The mechanical action depends on the drum size and load (a small load in a large drum is exposed to greater mechanical action than a fully loaded small-drum machine). Once the size is fixed, to reach a minimum washing performance, the optimum energy efficiency performance can be achieved by extending the duration (therefore extending mechanical action) and lowering the washing temperature.

Since it is more energy-efficient to increase mechanical action than to increase temperature, the optimisation of programmes by the manufacturers has been by proposing long-duration programmes at lower temperatures.

The inclusion of a penalisation time-based parameter in the EEI would reduce the benefits of excessive extension of programme times. Such a change would set new conditions and open up a completely new playing field for competition among the manufacturers to develop efficient but not too lengthy programmes, stimulating machine designers to find other innovative technologies.

On the negative side, this option can be perceived as a less transparent option for consumers, because the label included is endogenous to other parameters besides just energy, and the energy efficiency classification does not provide a direct correlation with the energy consumption declared on the lower part of the label. This means also that the washing machines with lower energy consumption but longer programme duration will no longer achieve the best EEI. Lower energy consumption will decrease the EEI value, whereas longer programme duration will increase it.

The full consequences of this option are uncertain: the development of market players in reaction to the measure is unknown. Manufacturers would have to find trade-offs between the energy consumption and programme duration of the cycles to achieve good $\mathrm{EEI}_{\mathrm{E} \& \mathrm{t}}$ indexes, and the optimisation may not develop in the direction of the overall energy saving for the EU which is the goal of the EU regulator to achieve. This measure would affect both the Ecodesign and the Energy Labelling regulations.

(c) Restrictions or limitations to the programme duration (e.g. a time cap). This measure will be modelled below under the 'programme duration cap' scenario.

The observed trend of increasing the programme duration above $3 \mathrm{~h}$ bears the risk that the efficient programmes are not used in real life by consumers. This trend can be limited by means of a programme duration cap. A limitation of the programme duration to around 3-4 h will force the manufacturers to develop efficient programmes within these limits while continuing to 
achieve the required washing performance. This measure would fix one of the parameters of Sinner's Circle which has been used by the manufactures to compensate the lower washing temperatures and reduces the size of the playing field. A possible consequence is that machines are less varied regarding their energy efficiency, which initially not only increases the incentives for differentiation but also reduces it if no technical solutions are found. Should the latter happen, this measure could become a barrier to successful implementation of the energy label, as one of its aims is to differentiate products on the market. If no technological solution is found and the only technical option to compensate duration is an increase in temperature, this measure could result in a higher average energy consumption of the standard cotton programmes.

\section{Description of the model}

A model for assessing the impacts of the different measures was created. The model sets up a stock for the coming years (2015-2030) and calculates the impact of the different measures regarding resource use (energy and water), emissions $\left(\mathrm{CO}_{2 \mathrm{eq}}\right)$ and consumer expenditure. These impacts also depend on the market evolution of household washing machines at the European level (EU-28). A summary of the inputs of the model and the sources of information are provided in Table 1.
Data on the energy consumption of washing machines are based on the performance data provided by the manufacturers, data from consumer surveys and the evolution of the technology in this appliance.

First of all, the model estimates the overall stock of washing machines in Europe based on the number of households (Eurostat 2016a) and the estimated penetration rate (CLASP 2013). The total annual sales are subsequently estimated as the increase in the stock plus the machines sold to replace the discarded machines from the stock. The discarded machines are estimated by means of a Weibull cumulative function as is commonly done in the literature (US EPA 2015). Specific annual parameters introduced in the Weibull distribution depend on the age of the stock (Balde et al. 2015). These parameters include the expected lifetime of the washing machines (Prakash et al. 2016).

The model determines the average annual energy and water consumption of the washing machines by multiplying the per cycle energy and water consumption of the estimated testing portfolio programmes by the number of cycles per year (220 cycles/year) which is then multiplied by a correction factor to achieve the estimated energy and water consumption under the actual use conditions. The correction factor equals the ratio of the annual energy consumption under actual use conditions and the annual energy consumption declared by the manufacturers and based on the current performance standard.

Table 1 Inputs to the model for assessing the impacts of the four scenarios

\begin{tabular}{lll}
\hline Input & Value & Reference \\
\hline Expected lifetime & 12.5 years & Prakash et al. (2016) \\
Cycles per year & 220 cycles/year & Standard IEC 60545:2010 \\
Rated capacity & $7 \mathrm{~kg}$ & Average rated capacity APPLIA database (2014) \\
Manufacturing cost $\left(P_{0}\right)$ & $296 €_{2015}$ & Own assumption \\
Learning curve exponential $(b)$ & 0.3 & Obtained by fitting to the Eurostat (2016a) \\
Manufacturers' mark-up & 1.28 & Ruedenauer et al. (2011) \\
Retailers' mark-up & 1.26 & \\
VAT & $22 \%$ & \\
Energy price forecast & Series & PRIMES (2016) \\
Water escalation factor & $2.5 \%$ & Own assumption \\
Detergent cost & $44.8 €_{2015} /$ year & JRC (2015) \\
Cost of repairing (machines without heat pump) & $155 €_{2015}$ & Prakash et al. (2016) \\
Percentage of repair & $30 \%$ & \\
Cost of repairing (machines with heat pump) & $200 €_{2015}$ & Own assumption \\
Percentage of repair & $30 \%$ & Own assumption \\
\hline
\end{tabular}


Finally, technical data permitting the analysis of the washing machine performance have become available thanks to the manufacturers and European manufacturers' associations (APPLIA). The basis of this assessment is an engineering analysis of the possible improvement options and their costs combined with an impact analysis which calculates the impacts in the EU of replacing commonly used machines with more efficient ones. More details about the single and combined improvement options that were assessed regarding their energy-saving potential and additional costs can be found in JRC (2017a).

The purchase price of each machine for final consumers is estimated based on the manufacturing costs of the base washing machine and, when appropriate, the additional costs of the improvement options, mark-ups of the manufacturers and retailers and the VAT. In this model, two mark-ups have been used: one from the manufacturers to the retailers and one from the retailers to the consumers. These amounts take into account overhead costs and profits.

The manufacturing cost of a product decreases over time because of, among other reasons, the manufacturer's experience in producing that product. Thus, the forecasted manufacturing cost was corrected by the learning curve as $Y(j)=a X(j)^{-b}$, (McNeil and Bojda 2012). The learning curve factors ( $-b$ and $a$ ) were adjusted to fit the evolution of the harmonised consumer price index provided by Eurostat (2016b) while considering $a$ as the initial purchase price that equals the average price in 2014 (EUR 148). Finally, the operation costs include the electricity and water costs, maintenance and repair costs and costs of auxiliaries (detergents). Forecasted costs of the utilities were estimated based on the information provided in Table 1 and the cost of maintenance and repair, as well as the auxiliaries, was assumed to be constant.

The energy consumption of the overall stock of washing machines at EU-28 level per year is calculated as follows:

$\operatorname{AEC}_{\mathrm{EU} 28(j)}=\sum_{i=1}^{j} \operatorname{survival}_{(j-i)} *_{\mathrm{UEC}_{(j-i)}}$

where $\mathrm{AEC}_{\mathrm{EU} 28}(j)$ is the EU-28 annual energy consumption in year $j$, survival $(j-i)$ is the number of units surviving in year $j$ which entered the stock in year $j-i$ and UEC is the average unitary energy consumption of a machine in the year $j-i$ in which the product was purchased as a new unit. The average energy consumption of a machine is calculated from the distribution of the sales over the label classes in the year when it was purchased. The energy and water consumption of each washing machine in a certain label class is calculated at the maximum value of the EEI of that energy efficiency class. GHG emissions are estimated based on the annual electricity consumption multiplied by the emission factor given in Table 2 .

To calculate the EU-28 cost for electricity use by washing machines, $\mathrm{AEC}_{\mathrm{EU} 28}(j)$ is multiplied by the corresponding cost for electricity per kilowatt hour in year $j$. The same approach is applied for calculating the water cost at the EU-28 level, in accordance with Table 1. The values for the electricity and water prices in the period are gathered in Table 2. The repair and maintenance costs include costs associated with repairing or replacing components that have failed and costs associated with maintaining the washing machines. The repair and maintenance costs are assumed to be constant, as is the cost of detergents.

Description of the scenarios

As mentioned in the previous sections, one reason why consumers do not use the current testing programmes

Table 2 Annual energy prices, water prices and emission factors from electricity use

\begin{tabular}{lccc}
\hline Year & $\begin{array}{c}\text { Energy price } \\
(\mathrm{EUR} / \mathrm{kWh})\end{array}$ & $\begin{array}{l}\text { Emission factor } \\
\left(\mathrm{g} \mathrm{CO}_{2} / \mathrm{kWh}\right)\end{array}$ & $\begin{array}{l}\text { Water price } \\
\left(\mathrm{EUR} / \mathrm{m}^{3}\right)\end{array}$ \\
\hline 2015 & 0.190 & 395 & 4.08 \\
2016 & 0.193 & 392 & 4.19 \\
2017 & 0.195 & 389 & 4.29 \\
2018 & 0.198 & 386 & 4.40 \\
2019 & 0.200 & 383 & 4.51 \\
2020 & 0.203 & 380 & 4.62 \\
2021 & 0.204 & 376 & 4.74 \\
2022 & 0.205 & 372 & 4.85 \\
2023 & 0.207 & 368 & 4.98 \\
2024 & 0.208 & 364 & 5.10 \\
2025 & 0.209 & 360 & 5.23 \\
2026 & 0.208 & 356 & 5.36 \\
2027 & 0.208 & 352 & 5.49 \\
2028 & 0.207 & 348 & 5.63 \\
2029 & 0.207 & 344 & 5.77 \\
2030 & 0.212 & 340 & 5.92 \\
\hline
\end{tabular}

Source: PRIMES 2016 
(so-called standard and optimised by the manufacturers) is their long duration. The distribution of the arithmetic mean programme duration of three current testing programmes - the standard cotton $60^{\circ} \mathrm{C}$ at full capacity, standard cotton $60{ }^{\circ} \mathrm{C}$ at half capacity and standard cotton $40{ }^{\circ} \mathrm{C}$ at half capacity-is shown in Fig. 3. It can be seen that the average programme duration varies from approximately 130-300 min. Most of the models have an average programme duration between $160 \mathrm{~min}$ and $220 \mathrm{~min}$.

The revision of the Ecodesign (1015/2010) and Energy Label regulation (1061/2010) on washing machines offers an opportunity to revise the existing requirements and address issues such as the reluctance of consumers to use long energy-saving programmes.

The policy measures investigated in this study have been formulated as scenarios and are compared to a business-as-usual (BAU) scenario. The BAU scenario implies no changes in the legal requirements for washing machines, except the rescaling of the energy label of washing machines into the A to $\mathrm{G}$ scale, as prescribed by the Energy Labelling Framework regulation (EU) No $1369 / 2017$.

\section{Scenario 0: Business-as-usual}

The only change introduced in the BAU scenario compared to the current conditions is the rescaling of the energy label scale into an A to G scale, as it was already known that the rescaling would have to take place shortly. The rescaling of the energy label is expected to have a slightly positive impact on the energy performance evolution of the machines in comparison to the current situation. Currently, the energy efficiency class $\mathrm{A}+++$ dominates in the European market, as shown in Fig. 4. According to the APPLIA database (2016), 75\% of washing machines declared an A+++ classification, $15 \%$ an A++ classification and approximately $10 \%$ an A+ classification.

In accordance with the Energy Label Framework regulation (EU) No. 1369/2017 and considering that washing machines are considered a slow-moving technology (the speed of technical development is not as fast as other products such as ICT products), the revision of the energy label for washing machines should consist of seven energy efficiency classes, from A to G. The newly rescaled label shall have one empty top class at the time of writing, to encourage technological progress, to provide regulatory stability and to limit the frequency of rescaling. This means that the empty top class incentivises the manufactures to optimise the energy performance of the machines while at the same time ensuring that only a small market share will reach this classification in the long term.

Several alternatives can be proposed for this exercise. Figure 5 shows a possible rescaling where the most efficient machines are classified as class B and the most populated class will be class F. The values for the EEI are shown by the class letter.

In the BAU scenario, it is assumed that the market will improve at the same rate and in the same direction as today. However, thanks to the rescaling of the energy efficiency label, in this study, it is considered that the label will recover part of its potential for differentiating among washing machines, and the manufacturers will have more incentives to go beyond the mandatory
Fig. 3 Average programme duration distribution of the standard cotton $60^{\circ} \mathrm{C}$ programme at full and half capacity and the standard cotton $40^{\circ} \mathrm{C}$ programme at half capacity. Source: APPLIA database (2016)

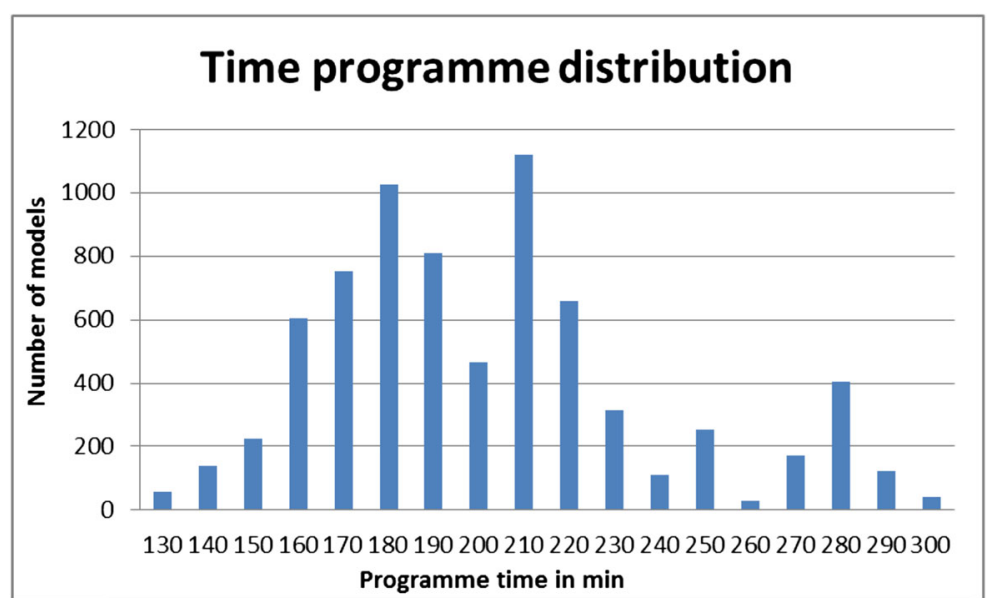


Fig. 4 Distribution of the energy label for washing machines on the market in 2016. Source: APPLIA database 2016

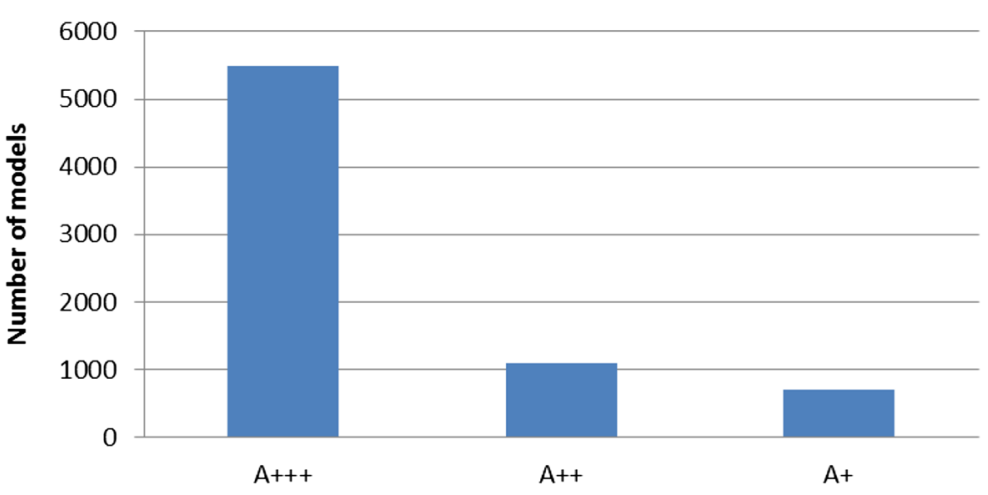

Ecodesign requirements and develop washing machines that will reach higher energy efficiency classes sooner than without a rescaling of the label.

These efforts are however not fully reflected in the energy consumption of washing machines under real use conditions as consumers are assumed to be reluctant to use long energy-saving programmes.

\section{Scenario 1: Information on the label}

Providing the programme duration information on the label does not affect the classification of the machine according to the energy efficiency label (same energy efficiency classification as in the BAU scenario). This measure, however, is expected to affect the sales. Due to the provision of this information, consumers will be aware of the long duration of the testing programmes and would make a more informed choice that will match better their needs.

Thus, it is assumed that there will be some consumers that will prefer shorter programmes and will demand machines with a worse energy efficiency classification and other consumers that will give prevalence to the energy efficiency classification and demand machines of the top energy efficiency classes but with longerlasting energy-saving programmes.

\section{Scenario 2: Energy efficiency index based on energy consumption and programme duration (EEI $E \& t)$}

The current EEI is only based on the energy consumption. If this parameter is modified by introducing a second parameter, the distribution of the classes on the label could be dramatically changed.

In the 'Energy efficiency index' section, the calculation of the current EEI has been explained in detail. This scenario proposes the introduction of a second parameter relying on the average programme duration as follows:

$\mathrm{EEI}_{\mathrm{E} \& \mathrm{t}}=A \frac{\mathrm{AE}_{c}}{\mathrm{SAE}_{c}}+B \frac{t}{t_{\mathrm{ref}}}$

with $A+B=1$ where $A=$ the correction factor for the annual energy consumption, $B=$ the correction factor for the average programme duration, $t=$ the programme duration and $t_{\text {ref }}=$ the reference programme duration.
Fig. 5 Possible rescaling of the energy label for washing machines in accordance with the Energy Label regulation (maximum and minimum values for the EEI are shown in the axis that correspond to the energy efficiency classes). Source: APPLIA database 2016

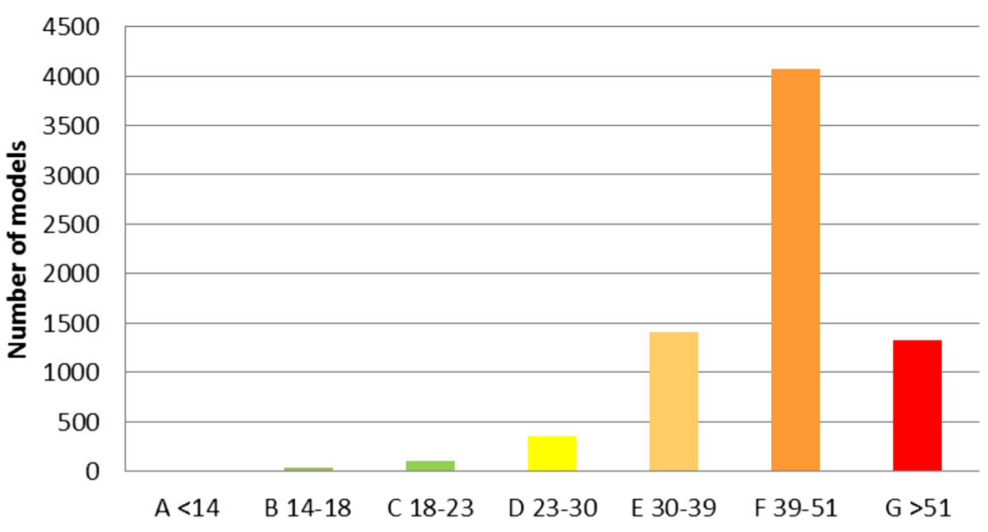


As observed, the formula is based on three parameters that are arbitrary. In order to analyse the effect of those parameters, three options have been studied for each parameter. The correction factor $A$ took the values of $0.8,0.7$ and 0.6; the correction factor B adopted the values $0.2,0.3$ and 0.4 , respectively; and the $t_{\text {ref }}$ the values of $180 \mathrm{~min}, 210 \mathrm{~min}$ and $240 \mathrm{~min}$.

For each of these options, the following classes have been proposed as shown on the $X$-axis of Fig. 6 . Figure 6 shows that the differences in the $t_{\text {ref }}$ factor does not strongly modify the distribution into the energy efficiency classes. However, factors A and B have a stronger influence. It is observed that the lower the value of factor A (e.g. 0.6) and consequently the higher the value of
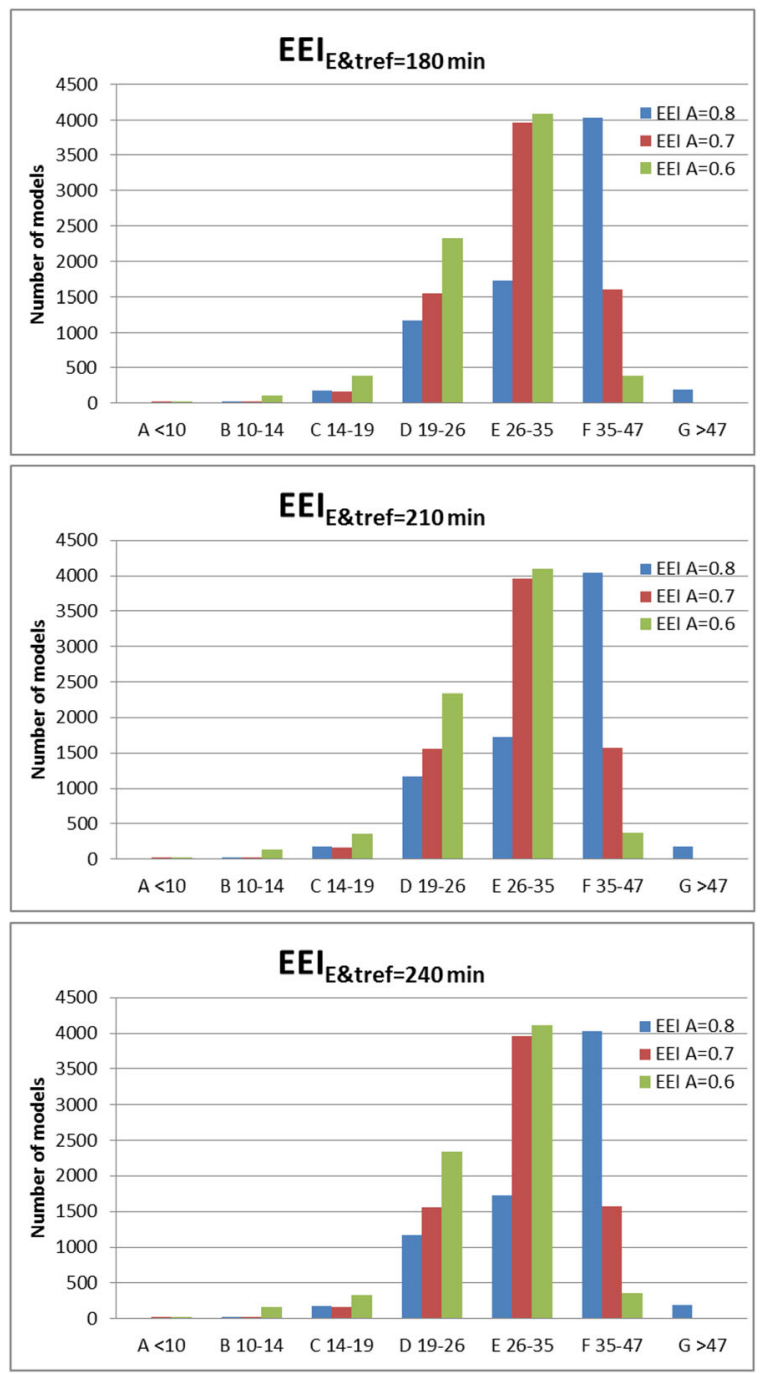

Fig. 6 Distribution of the washing machines under different calculation conditions of the $\mathrm{EEI}_{\mathrm{E} \& \mathrm{t}}$ factor B (e.g. 0.4), the broader the distribution. This means that the introduction of factors $\mathrm{A}$ and $\mathrm{B}$ into the formula helps in differentiating the performance of the products on the market.

Regarding the nine options under consideration, those in which factor A equals 0.7 and factor B equals 0.3 provide the broadest distribution for the three $t_{\text {ref }}$ values under study. In these cases, most of the machines are labelled as class E, followed by classes $\mathrm{F}$ and D. Some machines reach the top energy efficiency class (A) (around 15 models), meaning that the proposed rescaling should be revised to comply with the requirements of the Energy Labelling Framework regulation.

The evolution of the energy efficiency classes under these conditions is extremely difficult to determine, as no previous experience has been recorded. In theory, the introduction of the time parameter into the EEI formula opens a new field for competition that is no longer solely focused on the energy consumption. It is supposed that under these conditions, there will be manufacturers that will concentrate on the energy efficiency aspects while others will develop their products to offer shorter programmes. However, it is supposed that most of the manufacturers will try to find a trade-off between both parameters that simultaneously cover the needs of the consumers and reward the product with a relevant $\mathrm{EEI}_{\mathrm{E} \& \mathrm{t}}$.

Having a closer look at the distribution obtained by applying $A=0.7$ and $B=0.3$ and $t_{\text {ref }}=180 \mathrm{~min}$, the predominance of the energy consumption over the length of the programme duration can be seen. Table 3 shows the average energy consumption per cycle, aver-

Table 3 Share of models in 2016 and average rated capacity, energy consumption and programme duration for each energy efficiency class under scenario $\mathrm{EEI}_{\mathrm{E} \& \mathrm{t}}$

\begin{tabular}{llllll}
\hline $\begin{array}{l}\text { EL } \\
\text { class }\end{array}$ & EEI $_{\text {E\&t }} \begin{array}{l}\% \\
\text { models }\end{array}$ & $\begin{array}{l}\text { Average } \\
\text { rated } \\
\text { capacity } \\
\text { (kg cotton) }\end{array}$ & $\begin{array}{l}\text { Average } \\
\text { energy } \\
\text { consumption } \\
(\mathrm{kWh} / \mathrm{a})\end{array}$ & $\begin{array}{l}\text { Average } \\
\text { programme } \\
\text { duration } \\
(\mathrm{min})\end{array}$ \\
\hline $\mathrm{A}$ & $<9$ & $0.0 \%$ & & & \\
$\mathrm{~B}$ & $9-12$ & $0.3 \%$ & 8.33 & 60.40 & 226.27 \\
$\mathrm{C}$ & $12-16$ & $1.4 \%$ & 11.00 & 99.16 & 271.19 \\
$\mathrm{D}$ & $16-21$ & $5.2 \%$ & 8.71 & 118.33 & 244.21 \\
$\mathrm{E}$ & $21-27$ & $18.8 \%$ & 8.22 & 145.70 & 230.08 \\
$\mathrm{~F}$ & $27-35$ & $52.5 \%$ & 7.26 & 172.71 & 191.38 \\
$\mathrm{G}$ & $>35$ & $21.8 \%$ & 6.35 & 186.56 & 164.22 \\
\hline
\end{tabular}


age rated capacity and average duration for the refined energy efficiency classes. It can be seen that the washing machines classified with the lower energy efficiency classes account for the smaller average rated capacity, the higher average energy consumption and the shorter average programme duration. It can also be observed that the highest rated capacity is not classified in the top class (class B since class A should remain empty in accordance with the Energy Label Framework regulation). This indicates that the mismatch between the increasing rated capacity of the washing machines and the constant average loading of the consumers has been partially addressed.

\section{Scenario 3: Programme duration cap}

A programme duration cap is a clear message and may be an effective measure to force the market to move towards shorter washing cycles. As shown in Fig. 3 and in more detail in Table 4, if a programme duration cap was set and the manufacturers were not to shorten the testing cycles, there is a large number of models that would no longer be allowed into European market.

Table 4 shows that in general, the shorter the average duration of the testing programmes, the higher the energy consumption. The average of the weighted annual energy consumption of the machines with an average duration equal to or shorter than $180 \mathrm{~min}$ is $4.5 \%$ higher than the average weighted annual energy consumption of all the machines on the market. The weighted average energy consumption becomes closer to the weighted average energy consumption of all the washing machines provided that the programme duration cap is relaxed. For example, an increase in the energy consumption of approximately $2.10 \%$ would be observed if the programme duration cap was set at $240 \mathrm{~min}$.

Similarly, it is observed that the average rated capacity of the washing machines increases as long as the programme duration cap becomes less strict. Machines with an average duration equal to or shorter than $180 \mathrm{~min}$ have an average rated capacity close to $6.8 \mathrm{~kg}$ whereas those with an average duration equal to or shorter than $240 \mathrm{~min}$ have an average rated capacity of approximately $7.2 \mathrm{~kg}$. This indicates that smaller machines are able to provide shorter programme times.

Finally, Table 4 shows the number of models that comply with the programme duration cap depending on its strictness. A total of $60 \%$ of the models on the market in 2016 offered an average duration equal to or shorter than $180 \mathrm{~min}$. This percentage increases to approximately three quarters of the market if the programme duration cap is set at $210 \mathrm{~min}$ and reaches approximately $88 \%$ of the market if the programme duration cap is relaxed to $240 \mathrm{~min}$.

\section{Market evolution for the different scenarios}

The different scenarios act differently on the evolution of the resource consumption (energy and water) in the EU-28. There are two key factors that determine the consumption of resources in the model: (a) the annual energy and water consumption of an average washing machine under actual use conditions (which is not the same as the values declared on the energy label) and (b) the evolution of the sales in the coming years regarding the energy and water consumption (or how fast more energy-efficient washing machines are entering the EU market and the EU stock).

The estimation of the correction factors is based on the expected effects of the measure on the performance of the programmes and the use behaviour of consumers, regarding for example the selection and frequency of use of the programmes and the loading and type of clothes (JRC 2017a). The measures will affect not only the declared energy and

Table 4 Programme duration and energy consumption of the washing machines on the market

\begin{tabular}{llll}
\hline Time & Average annual energy consumption (kWh/year) & Average rated capacity (kg/cycle) & Number of models \\
\hline No limit & 167 & 7.338 & 7314 \\
$\leq 180 \mathrm{~min}$ & 174 & 6.824 & 3043 \\
$\leq 210 \mathrm{~min}$ & 172 & 7.044 & 5345 \\
$\leq 240 \mathrm{~min}$ & 170 & 7.184 & 6429 \\
\hline
\end{tabular}

Source: APPLIA Database 2016 
water consumption of the testing programmes but also the expected use of these and other programmes by the consumers. In this sense, it was assumed that shorter testing programmes (cotton programmes) will be better accepted by the consumers even if on average they have a higher energy and water consumption.

Additionally, the measures are expected to affect the purchase decisions of consumers as well as the evolution of the technology towards better energy efficiency classes. For example, setting a programme duration cap can prevent machines from being classified within the top classes in an A to $\mathrm{G}$ scale. Estimations of future sales are based on historical time series provided by the manufacturers (JRC 2017a). Table 5 shows the energy consumption and the forecasted sales distribution of the different energy efficiency classes for each of the measures under consideration. Water consumption and purchase price have been related to the energy consumption according to the following equations:
Purchase price $=$ Manufacture cost

$$
\left(1+\left(-05238 * \frac{\mathrm{EEI}_{j}-\mathrm{EEI}_{\mathrm{BC}}}{\mathrm{EEI}_{\mathrm{BC}}}-0.0899\right)\right)
$$

Water consumption $=\frac{220}{1000\left(0.6031 * \mathrm{EEI}_{j}-6.1931\right) .}$ These equations were empirically obtained by fitting the EEI value of a large number of models and their water consumption (in $\mathrm{m}^{3} /$ year) or their purchase price (in Euro 2015).

\section{Environmental and economic significance of the proposed measures}

The results of the modelling performed in this study foresee that the EU-28 total sales will remain stable in the coming years around 16.3 million units. The forecasted sales in 2030 consist of approximately $98 \%$ replacement sales (those machines bought to replace other machines that stopped working) because it is assumed

Table 5 Attributed energy consumption and forecasted sales for each of the energy efficiency classes for the BAU, information on the label, energy efficiency index $\left(\mathrm{EEI}_{\mathrm{E \& t}}\right)$ and programme duration cap scenarios

\begin{tabular}{|c|c|c|c|c|c|c|c|}
\hline & G & $\mathrm{F}$ & $\mathrm{E}$ & $\mathrm{D}$ & $\mathrm{C}$ & B & A \\
\hline \multicolumn{8}{|l|}{ BAU scenario } \\
\hline Energy consumption ( $\mathrm{kWh} /$ year) & 190 & 173 & 146 & 122 & 107 & 97 & 60 \\
\hline Sales 2020 & $15 \%$ & $46 \%$ & $26 \%$ & $10 \%$ & $2 \%$ & $1 \%$ & $0 \%$ \\
\hline Sales 2025 & $9 \%$ & $28 \%$ & $36 \%$ & $19 \%$ & $5 \%$ & $2 \%$ & $1 \%$ \\
\hline Sales 2030 & $5 \%$ & $16 \%$ & $43 \%$ & $24 \%$ & $8 \%$ & $2 \%$ & $2 \%$ \\
\hline \multicolumn{8}{|l|}{ Information on the label scenario } \\
\hline Energy consumption ( $\mathrm{kWh} /$ year) & 190 & 173 & 146 & 122 & 107 & 97 & 60 \\
\hline Sales 2020 & $14 \%$ & $43 \%$ & $27 \%$ & $13 \%$ & $1 \%$ & $1 \%$ & $1 \%$ \\
\hline Sales 2025 & $10 \%$ & $31 \%$ & $38 \%$ & $16 \%$ & $3 \%$ & $1 \%$ & $1 \%$ \\
\hline Sales 2030 & $8 \%$ & $20 \%$ & $45 \%$ & $20 \%$ & $5 \%$ & $1 \%$ & $1 \%$ \\
\hline \multicolumn{8}{|l|}{$\mathrm{EEI}_{\mathrm{E \& t}}$ scenario } \\
\hline Energy consumption $(\mathrm{kWh} /$ year $)$ & 187 & 172 & 145 & 118 & 99 & 60 & 58 \\
\hline Sales 2020 & $12 \%$ & $14 \%$ & $41 \%$ & $24 \%$ & $8 \%$ & $1 \%$ & $0 \%$ \\
\hline Sales 2025 & $8 \%$ & $12 \%$ & $35 \%$ & $27 \%$ & $15 \%$ & $2 \%$ & $1 \%$ \\
\hline Sales 2030 & $5 \%$ & $12 \%$ & $32 \%$ & $29 \%$ & $19 \%$ & $2 \%$ & $1 \%$ \\
\hline \multicolumn{8}{|l|}{ Programme duration cap scenario } \\
\hline Energy consumption (kWh/year) & 190 & 173 & 146 & 122 & 107 & 97 & 60 \\
\hline Sales 2020 & $16 \%$ & $45 \%$ & $29 \%$ & $9 \%$ & $1 \%$ & $0 \%$ & $0 \%$ \\
\hline Sales 2025 & $12 \%$ & $32 \%$ & $38 \%$ & $16 \%$ & $2 \%$ & $0 \%$ & $0 \%$ \\
\hline Sales 2030 & $10 \%$ & $20 \%$ & $45 \%$ & $18 \%$ & $5 \%$ & $2 \%$ & $0 \%$ \\
\hline
\end{tabular}


that the washing machine market is saturated and that the total number of washing machines in service will remain constant. The modelled and forecasted sales were compared to the available data and forecasted sales found in the literature. VHK (2014) predicted 14.9 million units would be sold in 2015 and 16.3 million units in 2030.

The different measures will impact differently on the evolution of the resource consumption (energy and water) in the EU-28. For all the scenarios, the overall energy and water consumption during the use phase of washing machines in the EU-28 is expected to decrease between 2015 and 2030 in comparison to the BAU scenario. This is due to the progress of technology development and the fact that the market is saturated.

The expected energy consumption and GHG emissions during the use phase are shown in Figs. 7 and 8. They show that the maximum energy savings are expected for the $\mathrm{EEI}_{\mathrm{E \& t}}$ scenario with an energy saving of $2.31 \mathrm{TWh} /$ year in 2030. This saving is about $8 \%$ of the washing machine energy consumption estimated under the BAU scenario in 2030. Note that the uncertainties associated with the $\mathrm{EEI}_{\mathrm{E} \& \mathrm{t}}$ scenario are the highest as it opens up a new playing field for competition and this makes it challenging to predict the evolution of the market. The scenario with the second greatest energy savings is the programme duration cap scenario. The energy savings expected due to the implementation of this measure are close to $0.97 \mathrm{TWh} /$ year in 2030 .

The modelling estimates that the scenario that introduces information on the label would result in higher energy consumption during the use phase at the EU-28 level in 2030 than the BAU scenario. This is due to the assumptions made of how consumers will consider this information at the time of purchase. It is assumed that some will select less energy-efficient machines and some others will purchase high-energy-efficiency products but not always use the energy-saving programmes. This scenario has thus large uncertainty about how consumers would react to the new information on the label, and whether they will be able to fully understand it, relate it to their needs and react rationally to it.

A forecast of GHG emissions during the use phase generated by the stock of machines on EU households is shown in Fig. 8. The GHG emissions have been estimated considering the electricity consumption and the conversion factors shown in Table 2. Figure 8 illustrates that the scenario with the inclusion of the programme duration in the EEI calculation $\left(\mathrm{EEI}_{\mathrm{E} \& \mathrm{t}}\right)$ would be the scenario saving most emissions (approx. 0.8 million tonnes $\mathrm{CO}_{2-\mathrm{eq}} /$ year in 2030). A scenario with a programme duration cap would also save some emissions (approx. 0.25 million tonnes $\mathrm{CO}_{2 \text {-eq }}$ year in 2030). Similarly to the results presented for energy consumption during the use phase, the scenario with the information on the label would increase emissions in comparison with the BAU scenario (approx. 1 million tonnes $\mathrm{CO}_{2-}$ eq (year in 2030).

With regard to the water consumption during the use phase of washing machines, maximum water savings of 25 million $\mathrm{m}^{3}$ per year are expected in 2030 due to the implementation of a programme duration cap. This is a saving of around $15 \%$ of the total water consumption expected in 2030 in the BAU scenario at EU-28 level.

Finally, with regard to the total consumer expenditure (Fig. 9), the measures implementing the information on the label as well as the programme duration cap lead to expected expenditures that are very close to the BAU
Fig. 7 Forecast electricity consumption of the stock of washing machines in the EU-28 under actual use conditions for the BAU, information on the label, $\mathrm{EEI}_{\mathrm{E} \& \mathrm{t}}$ and programme duration cap scenarios
Total real-life electricity consumption of the stock of WM in EU28

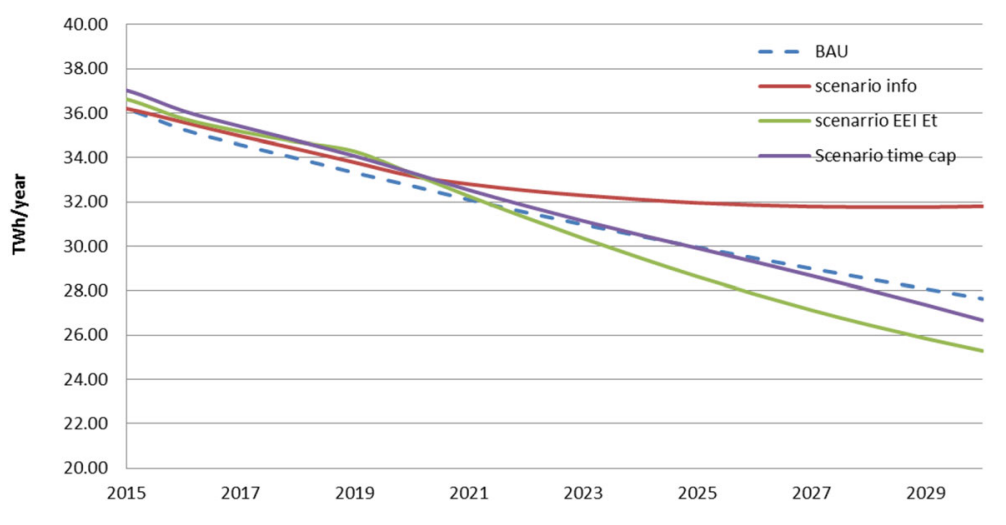


Fig. 8 Forecast of GHG emissions of the stock of washing machines in the EU-28 under actual use conditions for the BAU, information on the label, $\mathrm{EEI}_{\mathrm{E} \& \mathrm{t}}$ and programme duration cap scenarios

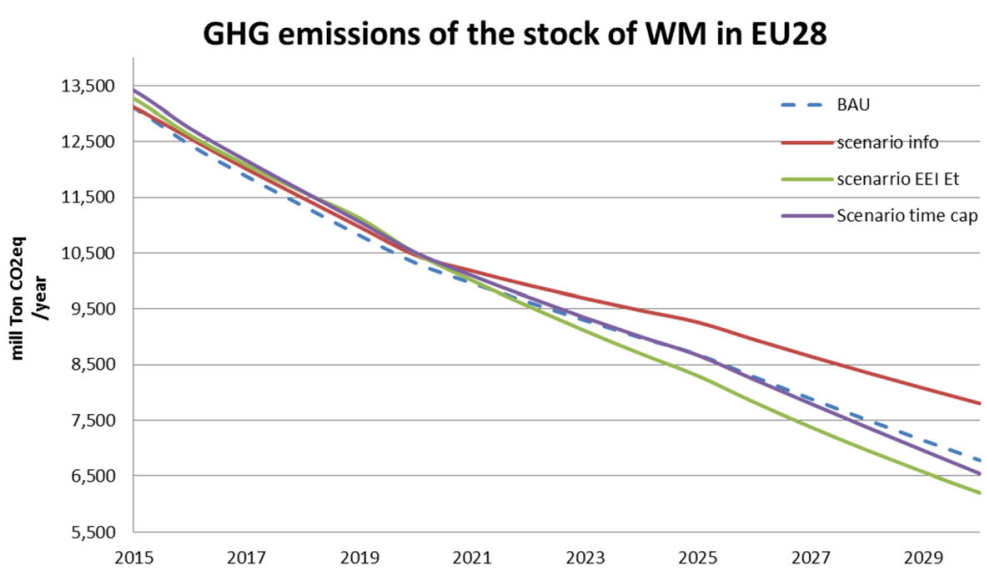

scenario. The measure implementing an additional parameter related to the duration in the calculation of the $\mathrm{EEI}\left(\mathrm{EEI}_{\mathrm{E \& t}}\right.$ scenario) forecasts higher consumer expenditure costs, which seems to be due to the higher purchase price of the appliances.

\section{Conclusions and policy implications}

The recent revision of the EU Energy Label and Ecodesign regulations for washing machines undertaken in 2014-2019 has been an opportunity to rethink the aspects where the regulations were not delivering the expected energy savings.

One of the aspects of the revision has been the observed divergence between the technical solutions offered by washing machine manufacturers to save energy, by means of long duration programmes, and the relatively low uptake of these programmes by consumers.
This paper focuses on this aspect of programme duration. The paper summarises the evidence of the problem and the policy measures that regulators and stakeholders have discussed, presenting the pros, cons, and technical details of regulative approaches that could bridge the gap and stimulate the manufacturers to offer consumers more energy-efficient appliances that operate for acceptable programme durations, closer to their actual needs.

Three possible regulatory measures were investigated: the provision of information about programme duration on the energy label, the inclusion of programme duration as an intrinsic parameter of the energy efficiency index (EEI) calculations and the setting of a programme duration cap. A bottom-up stock model was developed to quantify the environmental and economic implications of the three measures, comparing the options in terms of use of resources (energy and water consumption), emissions of $\mathrm{CO}_{2 \mathrm{eq}}$ during the use phase and expected costs along the life cycle of the product.
Fig. 9 Forecast consumer expenditure of the stock of washing machines in the EU-28 under actual use conditions for the BAU, information on the label, $\mathrm{EEI}_{\mathrm{E} \& \mathrm{t}}$ and programme duration cap scenarios
Consumer expenditure of the stock of WM in EU28

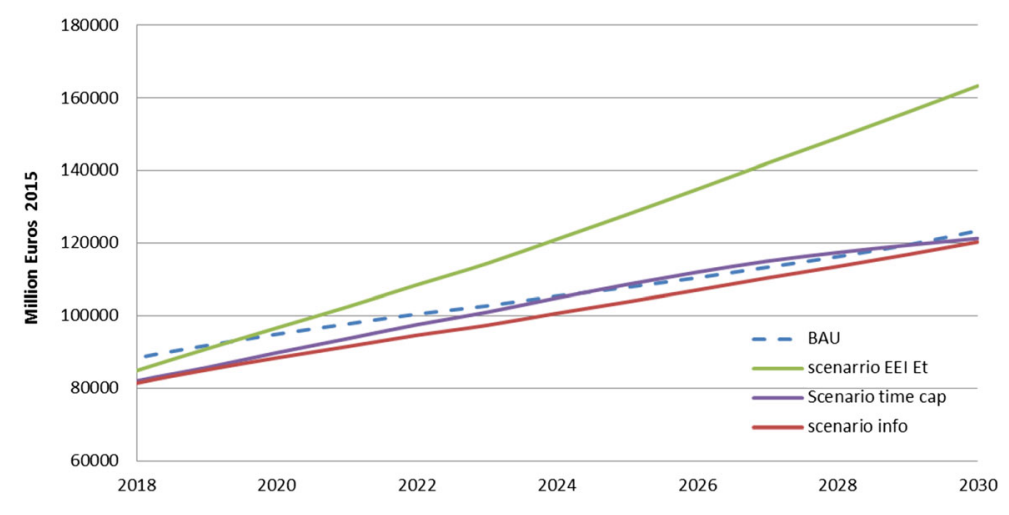


Of the three options, the inclusion in the EEI of an additional time parameter related to the duration of the programme would achieve the largest GHG and energy savings, the latter up to $2.31 \mathrm{TWh} /$ year by 2030 in the EU. However, this option has a high level of uncertainty because of the unknown development of market players in reaction to the measure. Manufacturers would have to find trade-offs between the energy consumption and programme duration of the cycles to achieve good $\mathrm{EEI}_{\mathrm{E} \& \mathrm{t}}$, and the optimisation may not develop in the direction of the overall energy saving for the EU which is the goal of the EU regulator to achieve. This measure would affect both the Ecodesign and the Energy Labelling regulations.

The measure with the second highest savings $(0.97$ $\mathrm{TWh}$ /year in 2030) was the introduction of a compulsory programme duration cap by means of an Ecodesign requirement. This measure assumes that shorter programmes (of less than $3 \mathrm{~h}$ ) will be acceptable to consumers if they deliver energy savings and thus will be used more often than the current energy-saving programmes lasting more than $4 \mathrm{~h}$. This measure delivers a high energy-saving potential and is relatively easy to implement, which is therefore advisable. The programme duration cap can, if necessary, be adjusted to the machine capacity, so larger machines have a larger cap to account for their higher energy efficiency per kilogrammes of clothes washed.

The provision of information about the duration of the programmes on the energy label was the third measure under consideration. It is assumed in this estimation that consumers understand the information provided by the energy label and are able to identify the machines on the market that better fit their needs, and it also assumes a willingness to accept the trade-off between programme duration and energy savings. This estimate is thus based on the assumption that consumers will react rationally to the measure and that the manufacturers will develop machines according to users' reactions. However, if consumers do not react to the presence of programme duration information on the label, energy efficiency alone will continue to be the aspect driving consumers' purchases, and the measure will not have the corrective action expected. In view of the arguments above, it is concluded that if this measure is implemented, it would be advisable to do so in combination with either of the other two mandatory measures investigated.
Acknowledgements Funding of this project by the European Commission is gratefully acknowledged. We thank CECED for their assistance and provision of updated and anonymised technical data. We thank Öko-Institute for their assistance in various stages of the study, and Mauro Cordella and the manufacturers for sharing their knowledge and experiences with us. The authors would like to thank participants and stakeholders for their fruitful discussions and informative sessions and to the anonymous referees for their comments and suggestions

Conflict of interest The authors declare that they have no conflict of interest

Open Access This article is distributed under the terms of the Creative Commons Attribution 4.0 International License (http:// creativecommons.org/licenses/by/4.0/), which permits unrestricted use, distribution, and reproduction in any medium, provided you give appropriate credit to the original author(s) and the source, provide a link to the Creative Commons license, and indicate if changes were made.

\section{References}

Alborzi, F., Schmitz, A., \& Stamminger, R. (2017a). Consumers' comprehension of the EU Energy Label for washing machines. Tenside Surfactants Detergents, 54(4), 280-290.

Alborzi, F., Schmitz, A., \& Stamminger, R. (2017b). Long wash cycle duration as a potential for saving energy in laundry washing. Energy Efficiency, 10(4), 823-838.

APPLIA database from 1997 to 2016.

Balde, C. P., Kuehr, R., Blumenthal, S., Fondeut Gill, S., Kern, M., Micheli, P., Magpantay, E., \& Huisman, J. (2015). E-waste statistics: guidelines on classifications, reporting and indicators: United Nations University. In IAS - SCYCLE Available at https://i.unu.edu/media/ias.unu.edu-en/project/2238/Ewaste-Guidelines_Partnership_2015.pdf.

Brazil, W., \& Caulfield, B. (2017). What makes an effective energy efficiency label? Assessing the performance of energy labels through eye-tracking experiments in Ireland. Energy Research \& Social Science, 29, 46-52.

CLASP (ed.) (2013). Estimating potential additional energy savings from upcoming revisions to existing regulations under the ecodesign and energy labelling directives: a contribution to the evidence base (http://www.clasponline.org). h t t p : / / w w w . c 1 a s p o n 1 i n e . org/en/Resources/Resources/PublicationLibrary/2013 /CLASP-and-eceee-Point-To-Additional-Savings-fromEcodesign-and-Energy-Labelling.aspx

Conrady, T., Kruschwitz, A., Stamminger, R., (2014) Influencing the sustainability of washing behavior by using motivational interviewing, Energy Efficiency 7(2), pp. 163-178

Ecofys. (2013). Evaluation of the Energy Labelling Directive and specific aspects of the Ecodesign Directive: Background report I: Literature review.

EU (2010a). Commission Regulation (EU) No 1015/2010 of 10 November 2010 implementing Directive 2009/125/EC of the European Parliament and of the Council with regard to 
ecodesign requirements for household washing machines. OJ L 293, 11.11.2010. OJ L 314, 30.11.2010.

EU (2010b). Energy Label Regulation (1061/2010). Commission Delegated Regulation (EU) No 1061/2010 of 28 September 2010 supplementing Directive 2010/30/EU of the European Parliament and of the Council with regard to energy labelling of household washing machines.

EU parliament. (2015). Energy Union: new impetus for coordination and integration of energy policies in the EU. Tracking European Commission priority initiatives in, 2015 Available a t : h t t p : / / w w w . e u r o p a r 1. e u rop a . eu/RegData/etudes/BRIE/2015/551310/EPRS_BRI(2015 )551310_EN.pdf.

Europa press (2017) available at http://europa.eu/rapid/pressrelease_IP-17-691_en.htm

Eurostat (2016a). Number of private households by household composition, number of children and age of youngest child ( 1000$)$. Available at http://ec.europa. eu/eurostat/en/web/products-datasets/-/LFS T_ HHNHTYCH, last accessed on 14 June 2016.

Eurostat (2016b). Harmonised Index of Consumer Prices (HICP): HICP $(2015=100)$ - monthly data (annual rate of change). Ava ilable at ht t p:// e c.e uropa . eu/eurostat/web/hicp/data/database, .

IEC 60545: 2010. Clothes washing machines for household use methods for measuring the performance.

JRC. (2015). A. Boyano, R. Kaps, J. Arendorf, K. Bojczuk, E. Sims, R. Menkveld, L. Golsteijn, A. Gaasbeek; Revision of the European Ecolabel Criteria for: laundry detergents and industrial and institutional laundry detergents; EUR 27380 EN; doi:10.2791/0171.

JRC. (2017a). Boyano Larriba, A., Cordella, M., Espinosa Martinez, M., Villanueva Krzyzaniak, A., Graulich, K., Rüdienuer, I., Alborzi, F., Hook, I. and Stamminger, R., Ecodesign and Energy Label for household washing machines and household washer-dryers, EUR 28809 EN, Publications Office of the European Union, Luxembourg, 2017, ISBN 978-92-79-74183-8, doi: 10.2760/029939, JRC108604.

JRC. (2017b). Bennett, M. J, Boyano A., Espinosa, N., Villanueva A. Follow-up for the preparatory study for the Ecodesign and Energy Label for household washing machines and household washer dryers, EUR 28807 EN, doi: 10.2760/954441.

Kruschwitz, A., Karle, A., Schmitz, A., \& Stamminger, R. (2014). Consumer laundry practices in Germany. International Journal of Consumer Studies, 38(3), 265-277.

McNeil, M., \& Bojda, N. (2012). Cost-effectiveness of highefficiency appliances in the US residential sector: a case study. Energy Policy, 45(2012), 33-42.

Pakula, C., \& Stamminger, R. (2015). Energy and water savings potential in automatic laundry washing processes. Energy Efficiency, 8, 205-222. https://doi.org/10.1007/s12053-0149288-0.

Prakash, S.; Dehoust, G.; Gsell, M.; Schleicher, T. \& Stamminger, R. in cooperation with Antony, F., Gensch, C.-O., Graulich, Hilbert, I., \& Köhler, A. R. (2016). Einfluss der Nutzungsdauer von Produkten auf ihre Umweltwirkung: Schaffung einer Informationsgrundlage und Entwicklung von Strategien gegen „Obsoleszenz“: Final report [Influence of the service life of products in terms of their environmental impact: Establishing an information base and developing policies against "obsolescence"].

PRIMES. (2016). EU reference scenario for 2016. Energy, transport and GHG emissions, Trends to 2050, European Commission, Directorate-General for Energy, DirectorateGeneral for Climate Action and Directorate-General for Mobility and Transport available at https:/ec.europa. eu/energy/sites/ener/files/documents/20160713\%20draft publication_REF2016_v13.pdf. Russoa A. C., Rossia M., Germania M., Favib C., (2018) Energy Label Directive: current limitations and guidelines for the improvement 2018, Procedia CIRP 69, 674 - 679.

Regulation (EU) 2017/1369 of the European Parliament and of the Council of 4 July 2017 setting a framework for energy labelling and repealing Directive 2010/30/EU.

Russo A.C., Rossia M., Germania M., Favi C., (2018), Energy Label Directive: Current Limitations and Guidelines for the Improvement, Procedia CIRP 69, 674-679

Ruedenauer, I., Blepp, M., Brommer, E., Gensch C., Graulich K., Mudgal, S., Cervantes, R., Faninger T., Lyons L., \& Seifried, D.. (2011) Preparatory studies for Ecodesign Requirements of energy-using products: Lot 24: professional washing machines, dryers and dishwashers; Final Report, Part Dishwashers. Available at: https://circabc.europa. e u/webdav / CircaB C / Energy/Energy \% 20 Efficiency/Library/Ecodesign $\% 20$ preparatory $\% 20$ studies/Lot $\% 2024 \% 20-\% 20$ Professional $\% 20$ washing $\% 20$ machines $\% 20$ and $\% 20$ dryers/Professional $\% 20$ washing $\% 20$ machines\%20and\%20dryers\%20-\%20Task\%206.pdf

Scheid, F., Lambert, E., Maitra, W., Gorny, S., Stamminger, R., et al. (2017) Textile quality depletion due to household machine wash - Ways to measure and impacts of wash duration and temperature on textiles, Tenside, Surfactants, Detergents 53(5), pp.438-444

Schmitz, A., Alborzi, F., \& Stamminger, R. (2016). Large washing machines are not used efficiently in Europe, Tenside, Surfactants. Detergents, 53(3), 227-234.

Textile testing institute, 2019, Sustainability in Commercial laundering, module 2: Machine Technology, Chapter 1: Sinner's circle, available at: https://www.texfinity. com/dynmedia/2366041858dcfba7d30d3bc20e2c1b18

US EPA. (2015). ENERGY STAR® Program Requirements Product Specification for Clothes Washers: Eligibility Criteria Version 7.0. http://www.energystar. gov/sites/default/files/specs//ENERGY\%20STAR\%20 Final\%20VersiEcodesign and Energy label revision: Household Washing machines and Washer-dryerson\%207.0 \%20Clothes\%20Washer\%20Program\%20Requirements.pdf

VHK (ed.) (2014 / status 2013). Ecodesign Impact Accounting: Part 1 - Status Nov. 2013. Available at: https://ec.europa. eu/energy/sites/ener/files/documents/2014_06_ecodesign impact_accounting_part1.pdf, last accessed on 7 April 2015.

Waechter, S., Sütterlin, B., \& Siegrist, M. (2015). The misleading effect of energy efficiency information on perceived energy friendliness of electric goods. Journal of Cleaner Production, 93, 193-202.

Publisher's note Springer Nature remains neutral with regard to jurisdictional claims in published maps and institutional affiliations. 